\title{
Degenerescência de batata-semente básica após um ou dois períodos de cultivo ${ }^{1}$
}

\author{
Julio Daniels²; Antônio Carlos F. Silva ${ }^{3}$; Zilmar S. Souza ${ }^{4}$; Jurema Schons ${ }^{5}$ \\ ${ }^{2}$ Embrapa Clima Temperado, C. Postal 403, 96.001-970 Pelotas-RS, E-mail: daniels@cpact.embrapa.br; ${ }^{3}$ EPAGRI, EE de Urussanga, C. \\ Postal 49, 88.840-000, Urussanga-SC, E-mail: ferreira@epagri.rct-sc.br; ${ }^{4}$ EPAGRI, EE de São Joaquim, C. Postal 81, 88.600-000, São \\ Joaquim-SC, E-mail: zilmar@epagri.rct-sc.br; ${ }^{5}$ UPF, C. Postal 611, 99.001-970, Passo Fundo-RS, E-mail: schons@fagro.upf.tche.br.
}

\section{RESUMO}

A infecção pelo vírus do enrolamento da folha da batata (Potato leafroll virus, PLRV) e pelo vírus Y da batata (Potato virus Y, PVY) constitui-se na principal causa da degenerescência da batata-semente no Brasil. Durante dois períodos de cultivo, setembro a dezembro de 1999 e março a junho de 2000, avaliou-se o percentual de infeção de batata-semente básica pelo PLRV e pelo PVY, em regiões produtoras de batata do Rio Grande do Sul e de Santa Catarina. No primeiro período foram avaliadas sorologicamente (DAS-ELISA) 623 amostras de nove regiões, observando-se percentagens de infeção de $17 \%$ para PVY e de 3\% para PLRV. A percentagem de infeção por PVY e PLRV em cada cultivar foi, respectivamente, Baronesa 7,5 e $0,3 \%$, Catucha 22 e $19 \%$, Elvira 42 e $0 \%$ e Monalisa 16 e $4 \%$. No plantio do segundo período usou-se parte dos tubérculos colhidos no primeiro, e foram avaliadas 301 amostras de duas regiões, constatando-se uma percentagem média de infeção de $58 \%$ para o PVY e de $11 \%$ para PLRV. A percentagem, por cultivar, foi Baronesa 67 e $6 \%$, Catucha 68 e 49\%, Elvira 94 e $2 \%$ e Monalisa 35 e $0 \%$.

\begin{abstract} periods

Degeneration of potato basic seeds after one or two planting

The infection by Potato leafroll virus (PLRV) and by Potato virus $Y$ (PVY) is the main cause of potato degeneration in Brazil. During two planting periods, September to December of 1999 and March to June of 2000 , the $\%$ of infection of basic potato seeds by PLRV and PVY was determined, on potato producer regions of Rio Grande do Sul and Santa Catarina States. In the first period, 623 samples from nine regions were serologically tested (DAS-ELISA), revealing 17 and 3\% of PVY and PLRV infections, respectively. The percentage of infection of cultivar Baronesa was 7,5 and 0,3\%, Catucha 22 and 19\%, Elvira 42 and $0 \%$, and Monalisa 16 and 4\%. In the second period part of the tubers harvested on the first one were planted, and 301 samples from two regions were tested, revealing a percentage of infection of $58 \%$ for PVY and $11 \%$ for PLRV. The percentage of infection of cultivar Baronesa was 67 and $6 \%$, Catucha 68 and 49\%, Elvira 94 and 2\%, and Monalisa 35 and $0 \%$.
\end{abstract}

Palavras-chave: Solanum tuberosum L., batata-semente, PVY, PLRV.

Keywords: Solanum tuberosum L., seed potato, PVY, PLRV.

(Recebido para publicação em 24 de agosto de 2001 e aceito em 19 de abril de 2002)

$\mathrm{N}^{3}$ as principais regiões produtoras de batata do Brasil, as temperaturas de inverno são amenas, raramente baixando a ponto de reduzir drasticamente a população de afídeos, fazendo com que insetos vetores de vírus permaneçam ativos durante todo o ano. Nestas condições, a batata-semente tende a degenerar muito rapidamente, destacando-se neste processo as infeções pelo vírus do enrolamento da folha da batata (Potato leafroll virus - PLRV) e pelo vírus Y da batata (Potato virus $Y$ - PVY), os dois principais vírus que afetam o cultivo da batata no país (Daniels, 1995; Figueira, 1995; Souza Dias, 1995). Embora a rapidez com que ocorre a degenerescência da batata seja influenciada pelo genótipo (Câmara et al., 1986; Filgueira \& Câmara, 1986; Daniels, 2000), a maioria das cultivares utilizadas atualmente no país exigem freqüentes renovações de tubérculos-semente para o plantio. Isto faz com que o custeio da lavoura seja muito elevado, pois as sementes representam de 30 a $50 \%$ deste valor.

Por outro lado, na Região Sul, a maioria dos produtores de batata pertence ao segmento da agricultura familiar, que não possui recursos para a renovação das sementes com a freqüência necessária, e planta em geral, tubérculossemente com altos índices de infecção virótica. $\mathrm{O}$ 'sementeiro', pequena lavoura de multiplicação de batata-semente feita pelo próprio produtor, tem sido recomendado para minimizar este problema (Costa, 1969; Daniels, 1983), porém, o seu sucesso depende, entre outros fatores, do manejo adequado.
O presente trabalho foi realizado visando determinar, após um e dois períodos de cultivo, a taxa de infeção pelo PLRV e PVY, de batata-semente básica das quatro cultivares mais plantadas em regiões produtoras do RS e SC.

\section{MATERIAL E MÉTODOS}

Os tubérculos básicos das cultivares Baronesa, Catucha, Elvira e Monalisa, utilizados neste estudo, com baixos percentuais de infecção por vírus (Tabela 1), foram obtidos na Embrapa $\mathrm{Ne}$ gócios Tecnológicos, Canoinhas (SC).

No período de setembro a dezembro de 1999, os sementeiros foram instalados em sete regiões produtoras do RS, representadas pelos municípios de Ibiraiaras, Morro Redondo, Pelotas,

1 Resultados parciais apresentados na VII Reunião Técnica Anual de Pesquisa e Extensão da Cultura da Batata da Região Sul do Brasil, Curitiba, PR e no XXXIV Congresso Brasileiro de Fitopatologia. 
Tabela 1. Percentagem de plantas com sintomas de viroses, nos campos de produção da semente básica, dos lotes utilizados nos sementeiros, conforme ficha da segunda inspeção fornecida pela Embrapa Negócios Tecnológicos, Canoinhas, SC, 1999.

\begin{tabular}{lcccc}
\hline Sintomas de virose & Baronesa & Catucha & Elvira & Monalisa \\
\hline Mosaico leve & 0,00 & 0,80 & 0,10 & 0,00 \\
Mosaico severo & 0,00 & 0,20 & 0,00 & 0,00 \\
Enrolamento da & 0,20 & 0,30 & 0,10 & 0,20 \\
folha & 0,20 & 1,30 & 0,20 & 0,20 \\
Total viroses & &
\end{tabular}

Tabela 2. Percentagem de tubérculos infectados pelo vírus do enrolamento da folha (Potato leaf roll virus, PLRV) e pelo vírus Y (Potato virus Y, PVY), após o cultivo, por um período, de batata-semente básica, em regiões produtoras do Rio Grande do Sul e de Santa Catarina. Período de setembro a dezembro de 1999.

\begin{tabular}{lcccc}
\hline \multirow{2}{*}{ Cultivar } & \multirow{2}{*}{ Caixas plantadas } & \multirow{2}{*}{ Amostras avaliadas } & \multicolumn{2}{c}{ Infeção (\%) $^{1}$} \\
\cline { 3 - 5 } & & & PLRV & PVY \\
Baronesa & 83 & 319 & $1(0,3)$ & $24(7,5)$ \\
Catucha & 13 & 72 & $14(19)$ & $16(22)$ \\
Elvira & 23 & 117 & 0 & $49(42)$ \\
Monalisa & 26 & 111 & $4(4)$ & $18(16)$ \\
\hline Total & 145 & 623 & $19(3)$ & $107(17)$ \\
\hline
\end{tabular}

${ }^{1}$ Detecção efetuada por DAS-ELISA, em plantas oriundas de tubérculos coletados antes da colheita.

Piratini, São Lourenço do Sul, Silveira Martins e Três Coroas, e em duas de SC, Planalto Catarinense, representada pelo município de Urupema e Litoral Sul Catarinense, representada pelos municípios de Criciúma, Jaguaruna, Pedras Grandes, São Martinho, Treze de Maio e Urussanga. As lavouras foram implantadas com três a quinze caixas de batata-semente, utilizando-se de uma a três das cultivares listadas acima, e foram conduzidas, basicamente, conforme as Recomendações Técnicas de Produção de Batata (Bisognin, 1996), embora não tenha havido uniformidade de critérios na condução das mesmas.

No período de março a junho de 2000 , foram instalados sete sementeiros na regiões da Encosta do Sudeste do Rio Grande do Sul, representada pelo município de São Lourenço do Sul e do Litoral Sul Catarinense, representada pelos municípios de Criciúma, Pedras Grandes, São Martinho e Treze de Maio, utilizando parte da produção obtida no primeiro plantio nestas mesmas regiões.

No final dos ciclos de cultivo, por ocasião da colheita, foram efetuadas amostragens, colhendo-se um tubérculo por planta, em número de quatro a seis plantas tomadas aleatoriamente na lavoura, por caixa de semente plantada. Ao todo, foram avaliadas, no primeiro plantio, 623 e, no segundo, 301 amostras. Após a brotação, um broto por tubérculo foi plantado em casa de vegetação e, da planta desenvolvida, uma folha central foi utilizada para análise sorológica através da técnica de DAS-ELISA (Clark \& Adams, 1977). Utilizou-se, para o PVY, um anti-soro disponível na Embrapa Clima Temperado (Daniels et al., 1987) e, para o PLRV, um anti-soro importado da Loewe Biochemica (Sauerlach, Alemanha). Consideraram-se positivas as amostras que deram um valor de absorbância de, pelo menos, duas vezes o valor dos controles negativos.

\section{RESULTADOS E DISCUSSÃO}

Das 623 amostras avaliadas no primeiro plantio, 107 (17\%) revelaram-se infectadas pelo PVY e 19 (3\%) pelo PLRV (Tabelas 2 e 3). As taxas de infeção pelos dois vírus (PVY e PLRV), por cultivar, foram respectivamente, Elvira 42 e $0 \%$, Catucha 22 e 19\%, Monalisa 16 e 4\% e Baronesa 7,5 e 0,3\% (Tabela 2). Das 301 amostras avaliadas no segundo plantio, $176(58 \%)$ estavam infectadas com o PVY e 34 (11\%) com o PLRV (Tabela 4). As taxas de infeção pelos dois vírus, por cultivar, foram, res- pectivamente, Baronesa 67 e $6 \%$, Catucha 68 e $49 \%$, Elvira 94 e $2 \%$ e Monalisa 35 e $0 \%$. Estes dados demonstram não apenas as diferenças de resistência das cultivares estudadas aos dois vírus, destacando-se a maior suscetibilidade da cv. Catucha e a maior resistência da cv. Monalisa ao PLRV, mas também, a crescente importância do PVY para o cultivo de batata no Sul do Brasil, que tem superado ao PLRV, constituindo-se na principal causa da degenerescência da batata-semente.

Com exceção da cv. Catucha, as taxas de infeção pelo PLRV foram surpreendentemente baixas, com índices de infeção, após dois períodos de cultivo, abaixo dos tolerados para batata-semente certificada (Rio Grande do Sul, 1997). Considerando que para cada $1 \%$ de incidência de PLRV há um decréscimo na produtividade de 0,75\% (Cupertino \& Costa, 1970) e que para maximização do custo/benefício da batata-semente, tolera-se índices de infeção pelo vírus de até 30\% (Souza Dias et al., 1984), a batata-semente básica poderia ser multiplicada pelos produtores por muitas gerações, não fossem as ocorrências de altas taxas de infeção pelo PVY.

Após o primeiro período de cultivo, a infeção da batata-semente pelo PVY, 
Tabela 3. Percentagem de tubérculos infectados pelo vírus do enrolamento da folha (Potato leaf roll virus, PLRV) e pelo vírus Y (Potato virus $Y$, PVY), após o cultivo, por um período, de batata-semente básica, em regiões produtoras do Rio Grande do Sul (RS) e de Santa Catarina (SC). Período de setembro a dezembro de 1999.

\begin{tabular}{lcccc}
\hline \multirow{2}{*}{\multicolumn{1}{c}{ Município (região) }} & Caixas plantadas & Testadas & \multicolumn{2}{c}{ Amostras } \\
\cline { 3 - 5 } & & 28 & 0 & PLRV \\
\hline lbiraiaras, RS & 15 & 66 & 0 & 0 \\
Morro Redondo, RS & 15 & 60 & 0 & $18(27)$ \\
Pelotas, RS & 15 & 60 & 0 & 0 \\
Piratini, RS & 15 & 91 & $4(4)$ & $2(3)$ \\
São Lourenço do Sul, RS & 20 & 60 & $1(2)$ & $9(10)$ \\
Silveira Martins, RS & 20 & 48 & 0 & $8(17)$ \\
Três Coroas, RS & 5 & 66 & $4(6)$ & $9(14)$ \\
Planalto Catarinense & 16 & 144 & $10(7)$ & $51(35)$ \\
Litoral Sul Catarinense & 24 & 623 & $19(3)$ & $107(17)$ \\
\hline Total & 145 & &
\end{tabular}

${ }^{1}$ Detecção efetuada por DAS-ELISA, em plantas oriundas de tubérculos coletados antes da colheita.

Tabela 4. Percentagem de tubérculos infectados pelo vírus do enrolamento da folha (Potato leaf roll virus, PLRV) e pelo vírus Y (Potato virus $Y$, PVY), após o cultivo, por dois períodos, de batata-semente básica, em regiões produtoras do Rio Grande do Sul (RS) e de Santa Catarina (SC). Período de março a junho de 2000.

\begin{tabular}{lcccc}
\hline \multirow{2}{*}{ Município (região) } & Cultivar & Testadas & \multicolumn{2}{c}{ Amostras } \\
\cline { 3 - 5 } & & & PLRV & PVY \\
\cline { 3 - 5 } & Baronesa & 66 & $4(6)$ & $44(67)$ \\
& Catucha & 19 & $11(58)$ & $13(68)$ \\
& Monalisa & 60 & 0 & $29(48)$ \\
\hline Total parcial & & 145 & $15(12)$ & $86(58)$ \\
\hline Litoral Sul Catarinense & Catucha & 40 & $18(45)$ & $27(67)$ \\
& Elvira & 52 & $1(2)$ & $49(94)$ \\
& Monalisa & 64 & 0 & $14(22)$ \\
\hline Total parcial & & 156 & $19(12)$ & $90(58)$ \\
\hline Total geral & & 301 & $34(11)$ & $176(58)$ \\
\hline
\end{tabular}

${ }^{1}$ Detecção efetuada por DAS-ELISA, em plantas oriundas de tubérculos coletados antes da colheita.

por região, foi de $35 \%$ no Litoral Sul Catarinense, $27 \%$ em Morro Redondo, $17 \%$ em Três Coroas e $17 \%$ em Silveira Martins (Tabela 3). Estes índices, altíssimos se comparados aos obtidos por Câmara et al. (1986), em Goiás, após a terceira multiplicação de sementes, revelam a importância deste vírus para o cultivo de batata na Região Sul. Além da suscetibilidade das cultivares, os fatores que, possivelmente, contribuíram para a rápida degenerescência da batata em relação ao PVY, foram aqueles observados anteriormente por Cupertino et al. (1972), ou seja, a presença de grandes populações de vetores e de plantas hospedeiras, bem como a proximidade de lavouras de batata infectadas.

\section{AGRADECIMENTOS}

Os autores agradecem à Mcknight Foundation, pelo financiamento parcial desta pesquisa, ao Técnico de Laboratório José Idalino do Amaral pelo apoio técnico na execução dos testes sorológicos, bem como aos colegas Edgar Noremberg, Francisco Antônio
Arduin de Arruda, Josemar Tolio Antonello, Luís Ernane Sachser, Orlindo da Silva Dutra, Soni Thurow, Nívio Luiz Lorenzet, José Carlos Nunes de Almeida, Claudino Madalosso, Natalício Nandi e Celito Bertelli pela implantação e acompanhamento dos sementeiros junto aos produtores.

\section{LITERATURA CITADA}

BISOGNIN, D.A. Recomendações técnicas para o cultivo da batata no Rio Grande do Sul e Santa Catarina. Santa Maria: UFSM. 1996. 64 p.

CÂMARA， F.L.A.; CUPERTINO， F.P.; 
FILGUEIRA, F.A.R. Incidência de vírus em cultivares de batata multiplicadas sucessivamente em Goiás. Fitopatologia Brasileira, Brasília, v. 11, n. 3, p. 711-716, 1986.

CLARK, M.F.; ADAMS, A.N. Characteristics of the microplate method of enzyme-linked immunosorbent assay (ELISA) for the detection of plant viruses. Journal of General Virology, v. 34, p. 475-83, 1977.

COSTA, D.M. Batata-semente, como obte-la melhor. Pelotas: Ministério da Agricultura-IPEAS, 1969. (IPEAS. Circular Técnica, 39).

COSTA, D.M.; CASTRO, L.A.S.; PETERS, J.A Batata: a busca de maior produtividade. Horti Sul, Pelotas, v. 1, n. 0, p. 40-42, 1989.

CUPERTINO, F.P.; COSTA, A.S. Avaliação das perdas causadas por vírus na produção de batata. I. vírus do enrolamento da folha. Bragantia, Campinas, v. 29, n. 31, p. 337-345, 1970.

CUPERTINO, F.P.; COSTA, A.S.; OLIVEIRA, A.R.; LEITE, N. Influência do vírus Y em lotes de batata-semente multiplicados sucessivamente. Revista de Olericultura, Campinas, p. 60-62, 1972.
DANIELS, J. Avaliação de genótipos de batata para resistência ao vírus Y. Horticultura Brasileira, Brasília, v. 18, n. 2, p. 145-147, 2000.

DANIELS, J. 'Sementeiro': opção para melhorar a sanidade da batata-semente no Rio Grande do Sul. Pelotas: EMBRAPA-UEPAE de Cascata, 1983. 5 p. (EMBRAPA-UEPAE Cascata. Comunicado Técnico, 26).

DANIELS, J. Produção de batata-semente no Rio Grande do Sul. Horti Sul, Pelotas, v. 3, n. 1, p. $12-$ $15,1994$.

DANIELS, J. Viroses da batata e suas implicações na produção de batata-semente no Rio Grande do Sul. Summa Phytopathologica, Piracicaba, v. 21, n. 3-4, p. 269-270, 1995.

DANIELS, J.; CASTRO, L.A.S.; PAIVA, E.; KULCZYNSKI, S.M. Obtenção e utilização de anti-soro para diagnose do vírus $Y$ da batata. Pelotas: EMBRAPA-CNPFT, 1987. 15 p. (EMBRAPA-CNPFT. Boletim de Pesquisa, 14).
FIGUEIRA, A.R. Viroses da batata e suas implicações na produção de batata-semente no estado de Minas Gerais: histórico do problema e soluções. Summa Phytopathologica, Piracicaba, v. 21, n. 3-4, p. 268-269, 1995

FILGUEIRA, F.A.R.; CÂMARA, F.L.A. Comportamento de cultivares européias de batata em gerações sucessivas. Horticultura Brasileira, Brasília, v. 4, n. 1, p. 29-31, 1986.

RIO GRANDE DO SUL, Secretaria da Agricultura e Abastecimento, Departamento de Produção Vegetal. Normas e padrões de produção de sementes para o estado do Rio Grande do Sul. Passo Fundo: Padre Berthier, 1997. 140 p.

SOUZA-DIAS, J.A.C. Viroses da batata e suas implicações na produção de batata-semente no estado de São Paulo. Summa Phytopathologica, Piracicaba, v. 21, n. 3-4, p. 264-266, 1995.

SOUZA-DIAS, J.A.C.; MIRANDA FILHO, H.S.; RAMOS, V.J.; COSTA, A.S.; IGUE, T. Produção de batata-semente Aracy com diferentes níveis de enrolamento. Fitopatologia Brasileira, Brasília, v. 9, n. 2, p. 203-211, 1984. 